\title{
Pulverized Maize Cob as a Recycled Agro Waste - A Feasibility Study
}

\author{
Vasudeva Nayaka KBL*, Rangaswamy BE
}

Department of Biotechnology and Research Center, Bapuji Institute of Engineering and Technology, Davangere, Karnataka -577004, India

\begin{abstract}
The global market for wood-based furnishings annually increases despite of decreasing availability of wood resources, especially in forest lacking regions, leading to the specific urge to search for alternatives. Agricultural residues are materials generated in large quantities and can accumulate at such an extent as to cause environmental problems. Maize cob powder was taken and mixed with Epoxy (Resin) and Hardener was added; the mixture was then molded into a frame and pressed for uniform surface and kept for air dry for 24 hours. Then the particle board was tested for its mechanical tests like tensile strength test, compression test, bending strength test were experimented.
\end{abstract}

Keywords: Particle Board; Maize Cob; Agro-residues; Epoxy; Mechanical and Physical properties

\section{INTRODUCTION}

In recent years, there is a growing tendency towards recycling of the waste and using it for producing the composite wooden products like particle board. On the other side depletion of forest has increased demand for these kinds of products. Particle boards are produced from agro-waste materials such as rice husk, jute sticks, waste wood, sugarcane wastes, water melon peels, maize cob, kitchen waste etc. These materials are non-toxic and are made from renewable or recyclable resources. Particle boards have many desirable properties such as high density, high surface hardness, abrasion resistance, high durability etc. Therefore the particle board has wide range of applications. This study aimed to evaluate the feasibility of using maize cob for the production of particle boards [1-3].

\section{Composite}

Composite material is a combination of two or more chemically different materials with distinct interface between them. The constituents maintain their separate identities (at least microscopically) in the composites, yet their combination produces properties characteristics that are different from those of the constituents. One of these constituents forms a continuous phase and is called matrix.

\section{Particle board}

Particle board has been manufactured from different varieties of raw materials in the form of small particles impregnated with resins or other appropriate binders reinforced together. The main difference between particle board and other conventional wooden boards is its material and the manufacturing process. Particle boards can be utilized for housing, industries, and in commercial buildings as partition walls, window entryway boards, table tops, board sheets and so on (Figure 1).

\section{MATERIALS USED IN PREPARATION OF PAR- TICLE BOARD}

\section{Raw material used}

Maize cob: Maize cobs are a by-product of the maize crop, consisting of the central fibrous rachis of the female inflorescence (the maize "ear"). While the whole maize ear (with the grains, with or without the husks) is also sometimes called as maize cob. Maize cobs are

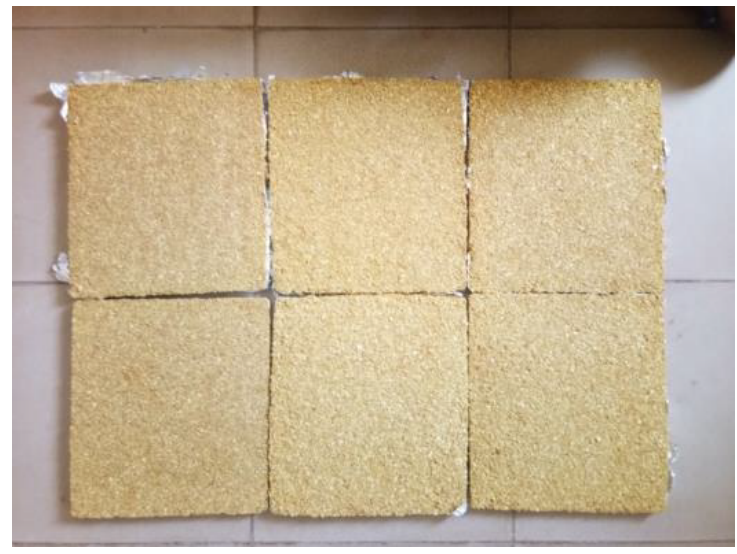

Figure 1: Particle Boards.

*Correspondence to: Vasudeva Nayaka KBL, Department of Biotechnology and Research Center, Bapuji Institute of Engineering and Technology, Davangere, Karnataka -577004, India, Tel: +9195350 93096; E-mail: vasudevnayaka@yahoo.co.in

Received: December 08, 2019; Accepted: February 16, 2020; Published: February 23, 2020

Citation: Vasudeva Nayaka KBL, Rangaswamy BE (2020) Pulverized Maize Cob as a Recycled Agro waste - A Feasibility Study. Int J Waste Resour 10:376. doi: $10.35248 / 2252-5211.20 .10 .376$

Copyright: $\odot 2020$ Vasudeva Nayaka KBL, et al. This is an open-access article distributed under the terms of the Creative Commons Attribution License, which permits unrestricted use, distribution, and reproduction in any medium, provided the original author and source are credited. 
a highly fibrous product with many agricultural and industrial applications. In agriculture, they are used for fuel, litter for poultry and other animals, mulch and soil conditioner, and as fodder for ruminants despite their low nutritive value. Their absorbency and abrasiveness makes them useful for several industrial applications. They can absorb finishing fluids, oil and water in industrial or environmental spills [4-6]. They are excellent carriers for vitamins and antibiotics in animal field, and for herbicides and pesticides in lawn care products. They are used for the production of chemicals such furfural or the sugar replacement xylitol. Maize cobs are used to blast and polish many materials, from jewelry, nuts and bolts, to golf club heads. More recently, maize cobs were reported to be a potential cheap and promising source for sustainable energy production (Figures 2 and 3).

\section{Chemicals used}

Epoxy resin (L12): Epoxy resins are a class of thermoset materials used extensively in structural and specialty composite applications because they offer a unique combination of properties that are unattainable with other thermoset resins [7]. Epoxies Offer high strength, low shrinkage, and excellent adhesion to various substrates, effective electrical insulation, chemical and solvent resistance, low cost and low toxicity (Figure 4).

\section{Characteristics of epoxy resin}

Versatility: Modification Properties like hardening methods.

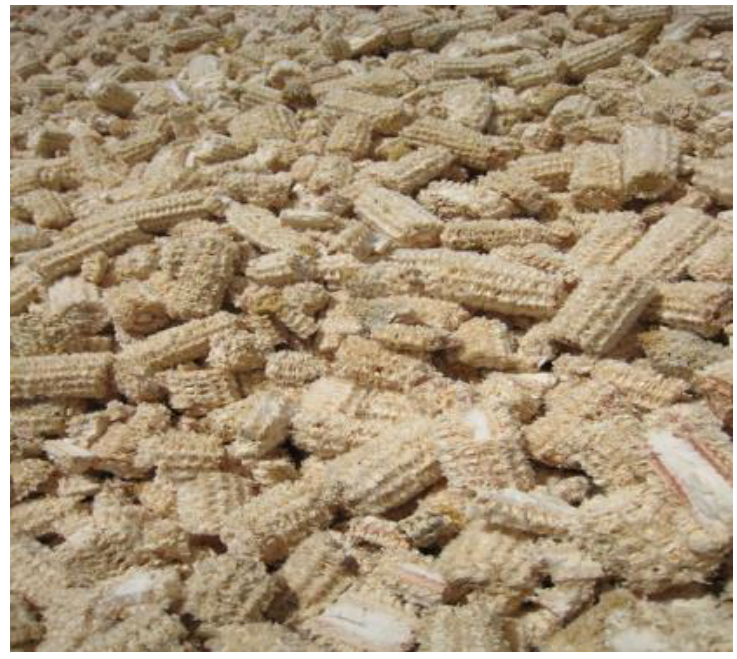

Figure 2: Maize Cob.

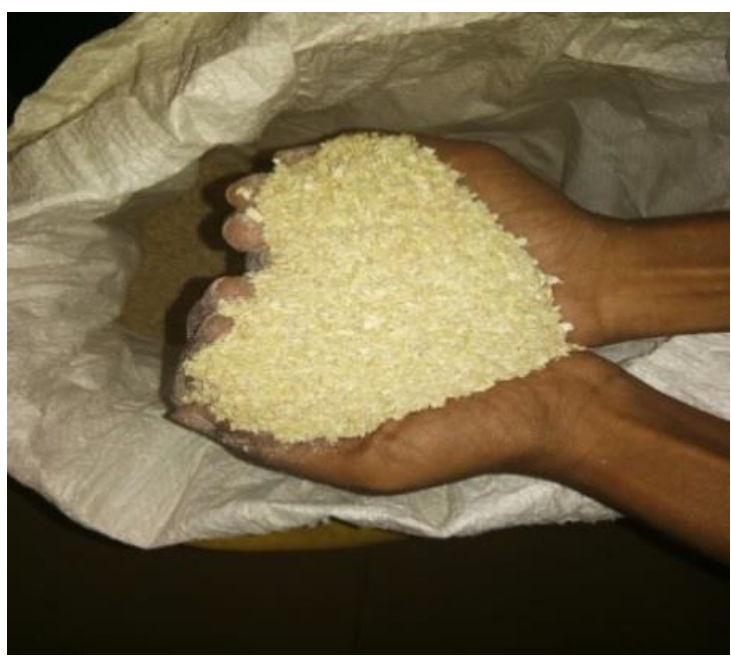

Figure 3: Maize Cob powder.

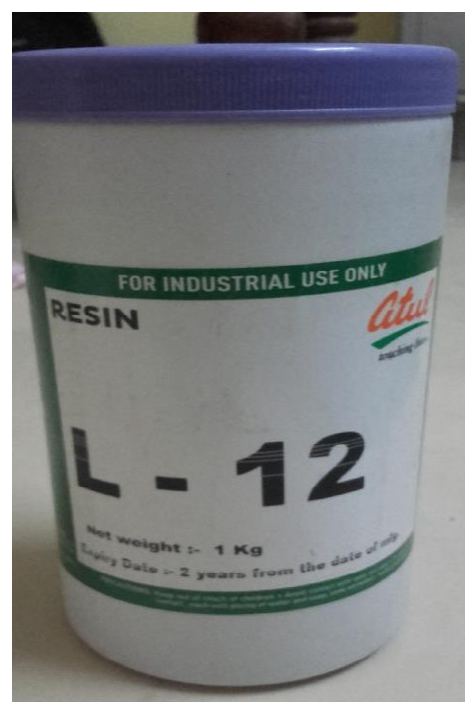

Figure 4: Epoxy (resin).

These resins possess several important properties, which make them unique among the variety of resins available.

Toughness: Cured epoxy resins are tough due to short distance between the cross linking points and the resins of the integral aliphatic chains.

Mechanical properties: Epoxy resin's systems and mechanical properties are due to their low shrinkage and relatively unstressed structure.

Electrical properties: Epoxy resin's good electrical properties over a wide range of frequencies and temperature. They are excellent insulating material having high dielectric strength, arc and tracking resistance.

Dimensional stability: Combination of many of the above properties contributes to the outstanding dimensional stability and permanence of epoxy resin's systems.

Water resistance: Epoxy resins are self-excellent moisture barrios exhibiting low water absorption and moisture transmission.

Hardener: The various forms and types of epoxy resin's, in their thermoplastic are uncured state are converted or hardened into useful thermosets by a reaction with variety of hardeners. These hardeners, curing agents, activators are catalyst may organic or inorganic, acidic or basic and of the room temperature or heat setting types.

Depending upon the resin and hardener compressing the system, the amount of hardener can vary low as one part of hardener per 100 parts of resin. The reaction between resin and hardener normally occurs without evolution of byproducts. Some hardeners promote curing by catalytic action and others directly participate in the reaction and are chemically bonded into resin chain (Figure 5).

The properties of hardener are as given below:

Color: Yellow,

Odor: Amine,

Physical state: Liquid,

Vapor Pressure: $<0.01 \mathrm{mmHg}$ at $20 \mathrm{deg}$ Celsius,

Boiling point: >200deg Celsius. 


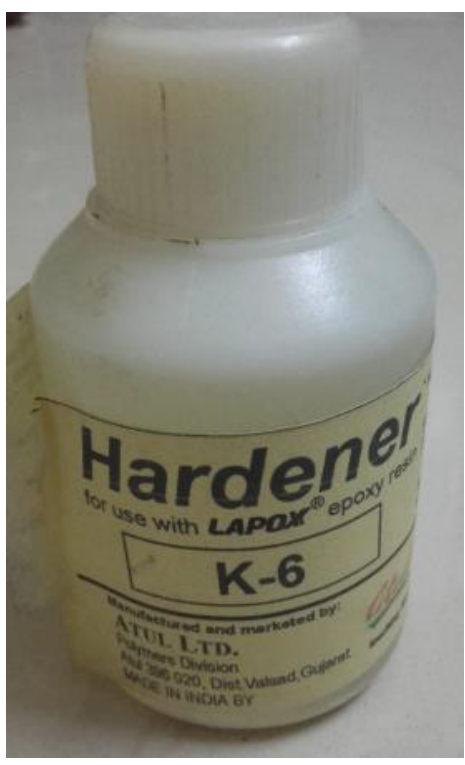

Figure 5: Hardener.

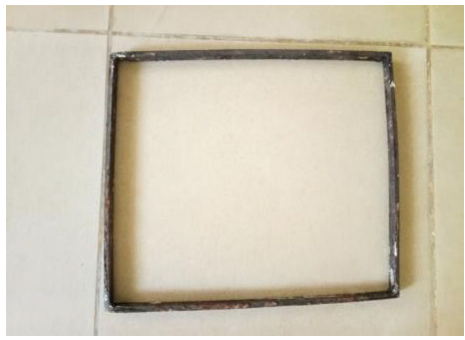

Figure 6: Molding Frame.

\section{Mold design}

Maize cobs are bought from the field and then they are powdered by pulverizer. Specimens are prepared by mixing cob powder, epoxy resin and hardener in suitable proportions. Molds are made to size of specimen concerned to the various tests conducted. Here, metal mold size $300^{*} 300^{*} 12 \mathrm{~mm}$ is used for preparing the particle board (Figure 6).

\section{Process description}

Particle Boards can be manufactured in desired shapes and sizes with suitable binders or fibers impregnating with resins such as Polyester, Urea Formaldehyde, Melamine Formaldehyde, Phenol Formaldehyde, Epoxy resins etc.

Drying: Sun drying is very simple and ancient skill used for drying of different waste. It is only possible in areas where in an average year the weather allows the waste to be dried immediately. The main advantage of sun drying is low capital and operating cost and also the fact that little expertise is required. Hence, it is primarily preferred for drying of raw materials for particle board making.

Segregation: Segregation of waste from its source is the primary step involved during the collection of raw materials for Particle board making. The different agro waste were stored and segregated at the source of generation itself. For example rice husk, saw dust, wood chips were segregated where it is generated from its source. In case of Municipal solid waste the segregation can be done as bio-degradable (Vegetables, fruits, kitchen waste, flowers, leaves etc.) and Non-biodegradable waste (plastics, metals, glass, paper etc.) Most of the bio degradable wastes segregated such as fruit peels, kitchen waste and leaves are being used for particle board production.
Shredding and grinding: Shredders vary in many ways according to the functions they perform. Shredding also employs grinder, chipper, granulator, hammer mills, shear shredder, speciality shredder and all-purpose shredders for size reduction, pulverization of materials to produce granulated products or powdered products of different waste like municipal waste, rice straw, wheat straw, wood chips, corn cob. The shredding process makes the handling of waste ease for the particle board making.

\section{Cob powder with epoxy}

Cob powder-Epoxy composite has properties which gives an edge over both cob powder and epoxy when mixed together in different proportions. Cob powder-epoxy exhibit better chemical and mechanical properties when compared to conventional wood. These particle boards would come out with better dimensional stability and fungal resistance when exposed to moist whether and they exhibit thermal linear expansion at adverse environmental condition. These boards have an ability to create more complex shapes and the products could be painted, screwed, nailed with some conventional tools for wood.

However the mechanical properties of the end product depend on the factors such as raw material selection, formulation, manufacturing technique and processing paramaters. There are several variable to consider when using cob powder as filler. Among them are moisture content, purity, particle size and species.

While the first three variables can be controlled by raw material selection and manufacturing process, species availability is often regionally influenced. It is important for the end user to be aware of the differences that species variations may have on their product. Increasing cob powder content will also affect the performance of the composite. With the increasing cob powder content mold shrinkage decrease and notched impact energy increases while unnotched decreases.

\section{Mixing procedure}

Following is the procedure for mixing the constituents of cob powder with epoxy.

1. The volume of the square mold is calculated and the corresponding proportions of cob powder, epoxy and hardener are measured according to the composition.

2. The weighed mixture of cob powder, epoxy is poured into a clean moisture free bowl and mixed well uniformly.

3. The hardener, corresponding to the amount of resin used is then poured and mixed well and left for few minutes.

4. The molten wax is applied to the inner walls of the mould for easy removal of casting.

5. The mixture is then poured into the mold and the surface is flattened with the flattener.

6. The flat plate is removed after 2 days by removing the side plates of the mold.

\section{Proportions of mixing}

Mixing of cob powder and epoxy resin is done according to the weight ratio:

The 3 types compositions are considered for this projects which will according to the ratio of cob powder to the epoxy resin mixed: 
1. $60: 40$ composition (specimen A),

2. 50:50 composition (specimen B),

3. 40:60 composition (specimen C).

\section{$60: 40 \%$ composition}

1. Cob Powder of about $60 \%$ of the weight of the mold is taken

2. Epoxy resin of about $40 \%$ of the weight of the mold

3. Next the hardener of adequate quantity is added to the mixture and mixed thoroughly.

\section{$50: 50 \%$ composition}

1. Cob Powder of about $50 \%$ of the weight of the mold is taken

2. Epoxy resin of about $50 \%$ of the weight of the mold

3. Next the hardener of adequate quantity is added to the mixture and mixed thoroughly

\section{0:60\% composition}

1. Cob powder of about $40 \%$ of the weight of the mold is taken

2. Epoxy resin of about $60 \%$ of the weight of the mold

3. Next the hardener of adequate quantity is added to the mixture and mixed thoroughly.

\section{Cutting of flat specimen}

The Flat plates are removed from the metal mold and are cut into required shapes and size, compatible for different tests (Figure 7).

\section{RESULTS IN TESTING OF PARTICLE BOARD COMPOSITE}

\section{Tensile test (ASTMD3039)}

Tensile strength is the maximum stress that a material can withstand while being stretched or pulled before falling or breaking. It is an important mechanical property of packing materials.

Tensile testing is also known as tension testing is a fundamental materials science test, 0 in which a sample is subjected to a control tension until failure. The results from the tests are commonly used to select a material for an application, for quality control and to predict how a material will react under other type of forces. Properties that are directly measured via a tensile test are ultimate tensile strength, maximum elongation and reduction in area.

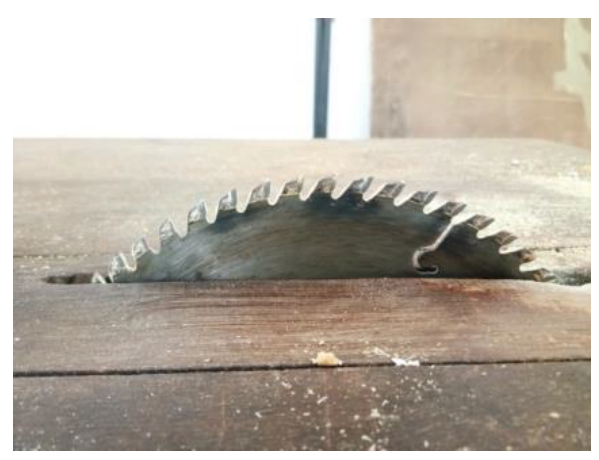

Figure 7: Cutting Blade.
Uniaxial tensile testing is most commonly used for obtaining the mechanical characteristics of isotropic materials. For isotropic materials such as composite materials and textiles, biaxial tensile testing is required (Figures 8 and 9).

Testing procedure for tensile test: In static tensile test, the operation is accomplished by gripping opposite ends of the specimen in the gauge of UTM and pulling it apart. In tensile test specimen elongates in the direction parallel to applied load.

Figures 10-12 shows standard specimen of tensile test. The specimen is kept symmetrically w.r.t longitudinal axis throughout its length in order to a avoid bending during the application of load.

One end of the tensile specimen is firmly gripped in the fixed head of the testing machine. Grip the other end of the specimen into the jaws of UTM. Apply load is applied and corresponding graphs are recorded in computerized system. Remove the broken specimen from the machine.

The above graph shows stress $\mathrm{v} / \mathrm{s}$ strain graph of tensile test for different proportions of cob powder and epoxy. We found that proportion $40: 60 \%$ (specimen C) has maximum stiffness and the proportion $60: 40 \%$ (specimen $A$ ) has minimum stiffness.

Thus we conclude that, as the percentage of epoxy increases in the specimens, the tensile strength also increases.

\section{Compression test (ASTMD3410)}

Compressive properties describe the behavior of a material when it is subjected to a compressive load. Loading is at a relatively low and uniform rate. This method determines in plain compressive properties by applying the compressive force into the specimen at the wedge grip interface. In this test, the specimen dimensions are

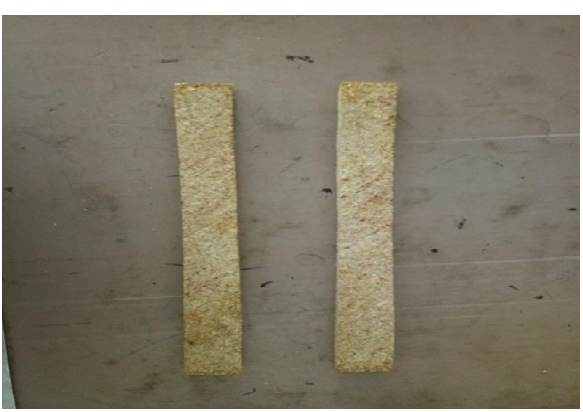

Figure 8: Specimen for tensile test.

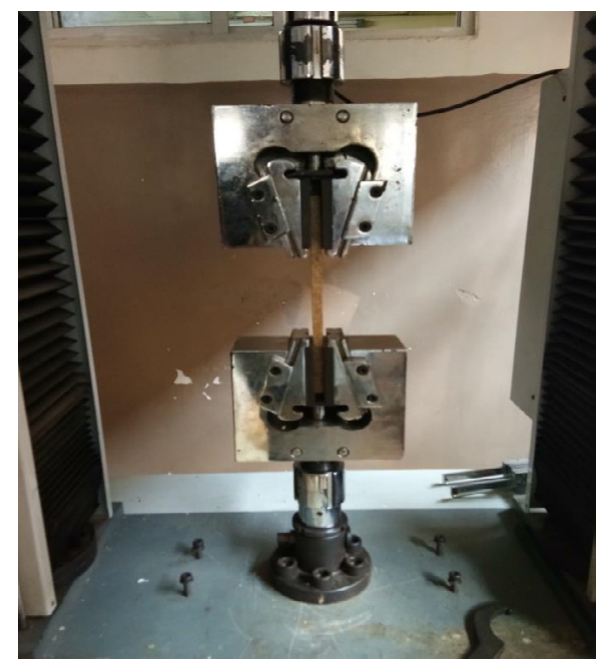

Figure 9: Setup for tensile strength testing. 


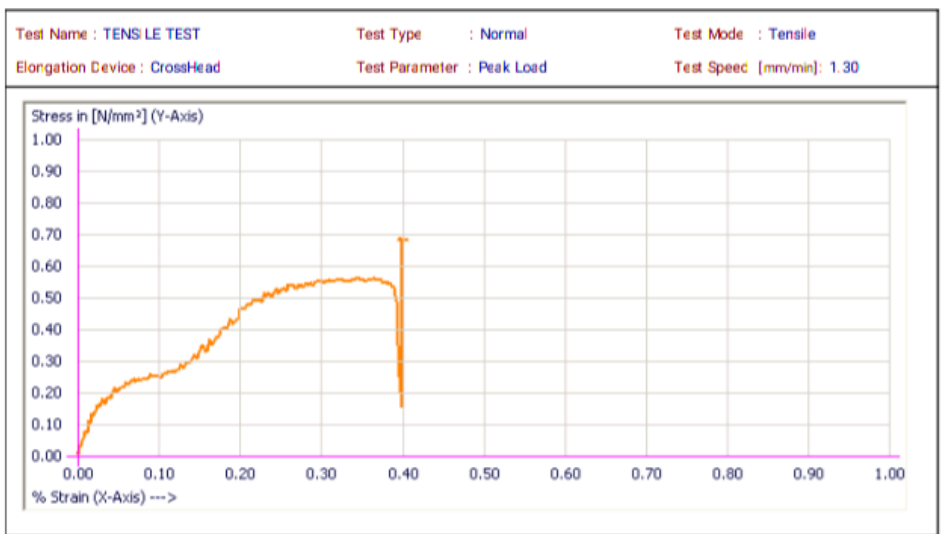

Sample Details :

\begin{tabular}{|c|c|c|c|c|c|c|}
\hline Sample No. & $\begin{array}{c}\text { CS Area } \\
\left(\mathrm{mm}^{2}\right)\end{array}$ & $\begin{array}{c}\text { Feak Loac } \\
(\mathrm{N})\end{array}$ & \% Elorgation & Break Load (N) & UTS (N/mm $\left.{ }^{2}\right)$ & $\begin{array}{c}\text { Yourgs } \\
\text { Noculus } \\
\left(\mathrm{N} / \mathrm{mm}^{2}\right)\end{array}$ \\
\hline 000001 & 250.00 & 172.00 & 0.41 & 4.66 & 0.69 & 168.92 \\
\hline
\end{tabular}

Figure 10: Tensile test of Specimen A.

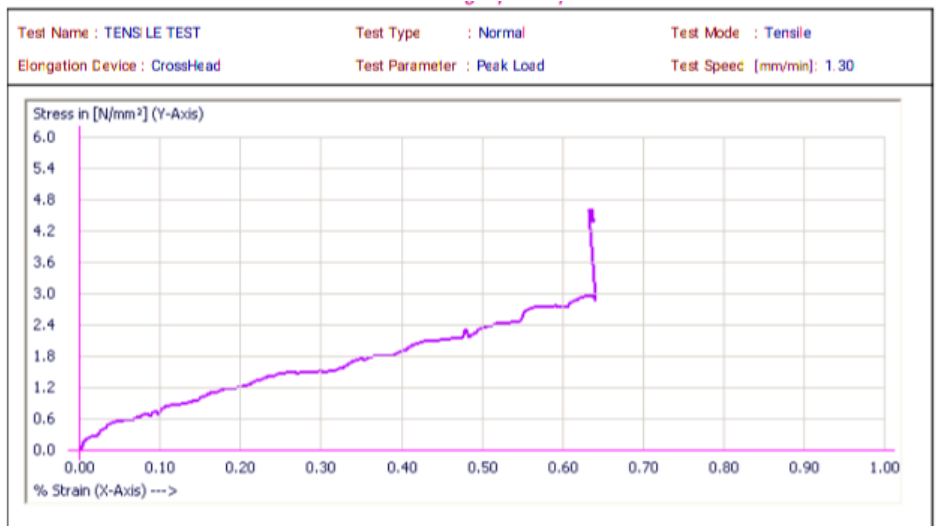

Sample Details :

\begin{tabular}{|c|c|c|c|c|c|c|}
\hline Sample No. & $\begin{array}{c}\text { CS Area } \\
\left(\mathrm{mm}^{2}\right)\end{array}$ & $\begin{array}{c}\text { Feak Loac } \\
(\mathrm{N})\end{array}$ & \% Elorgation & Break Load (N) & UTS $\left(\mathrm{N} / \mathrm{mm}^{2}\right)$ & $\begin{array}{c}\text { Yourgs } \\
\text { Noculus } \\
\left(\mathrm{N} / \mathrm{mm}^{2}\right)\end{array}$ \\
\hline 000002 & 250.00 & $1,150.00$ & 0.64 & 3.41 & 4.60 & 718.24 \\
\hline
\end{tabular}

Figure 11: Tensile test of Specimen B.

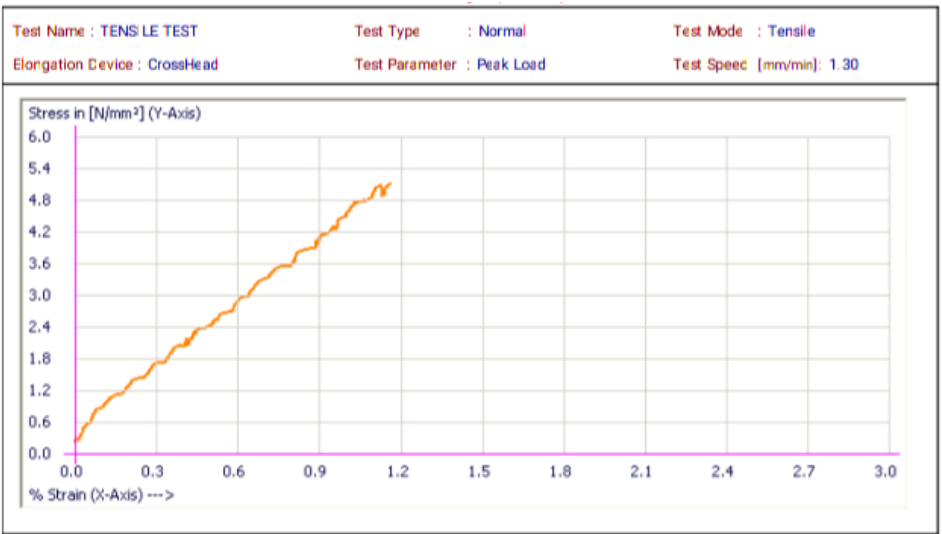

Sample Details :

\begin{tabular}{|c|c|c|c|c|c|c|}
\hline Sample No. & $\begin{array}{c}\text { CS Area } \\
\left(\mathrm{mm}^{2}\right)\end{array}$ & $\begin{array}{c}\text { Feak Loac } \\
(\mathrm{N})\end{array}$ & \% Elorgation & Break Load (N) & UTS $\left(\mathrm{N} / \mathrm{mm}^{2}\right)$ & $\begin{array}{c}\text { Yourgs } \\
\text { Noculus } \\
\left(\mathrm{N} / \mathrm{mm}^{2}\right)\end{array}$ \\
\hline 000001 & 250.00 & $1,274.00$ & 1.16 & $1,270.01$ & 5.09 & 438.18 \\
\hline
\end{tabular}

Figure 12: Tensile test of Specimen C.

according to ASTM standards. It is a cube of thickness $10 \mathrm{~mm}$ and width $1 \mathrm{~mm}$ (Figures 13 and 14).

Testing procedure for compression test: The arrangement for compression test is shown in the figure. In static compression test the operation is accomplished by placing the one end of the piece of the material on the work bench and the other end is left free. In this test, the specimen gets compressed in the direction of applied load.

The specimen must be selected to so as to give a reliable indication 
of the properties of the materials. The figure shows a standard specimen for compression test of composite material. The specimen must be symmetrical w.r.t. longitudinal axis throughout its length in order to avoid bending during the application of the load.

The above figure shows compression testing specimen is firmly placed at one end of the fixed lower head of the testing machine. Load is applied: peak load, percentage deformation, break load, compressive strength and young's modulus are recorded and corresponding graphs are obtained (Figures 15-17).

The above graph shows compressive properties for different proportions of cob powder and epoxy. Specimen with proportion

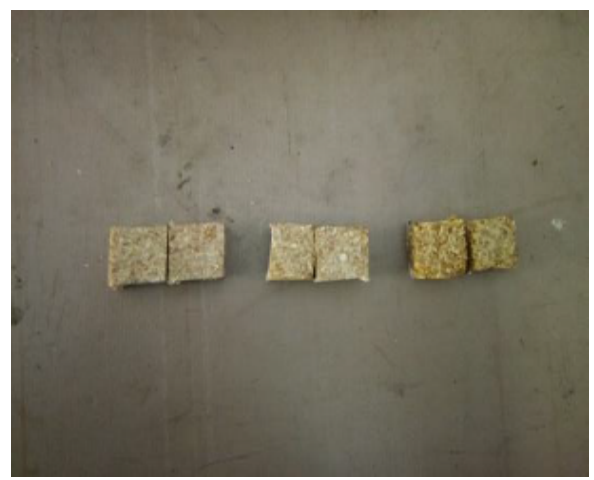

Figure 13: Specimens for compression test.

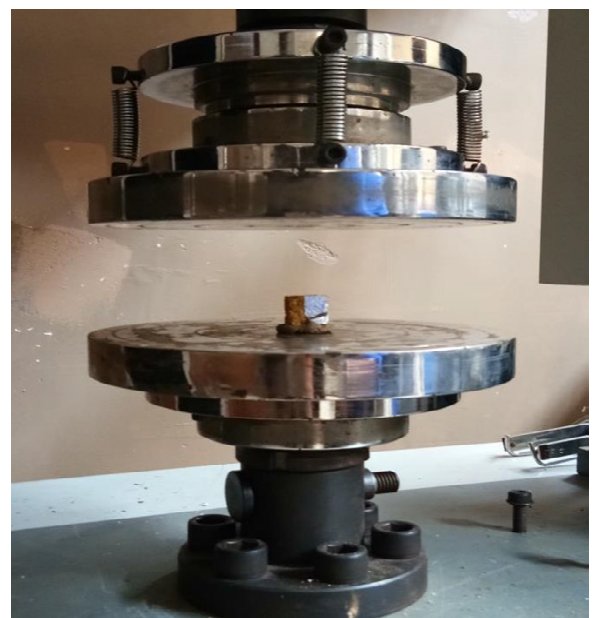

Figure 14: Setup for compression test.
$60: 40 \%$ (specimen A) shows the maximum compressive strength and on the other hand, specimen with proportion $40: 60 \%$ (specimen C) has the minimum compressive strength. This may be due to the fact that, less adhesive bonding with increase in the raw material content.

Thus we conclude that, as the percentage of cob powder increases in the specimen, the compression strength also increases.

\section{Bending test (ASTMD790M)}

In engineering mechanics, bending (also known as flexure) characterizes the behavior of a slender structural element subjected to an external load applied perpendicular to an axis of the element. When the length is considerably larger than the width and the thickness, the element is called a beam. The bending test measures the force required to bend a beam under 3 point loading conditions. The data is often used to select materials for parts that will support loads without flexing. Bending modulus is used as an indication of a material's stiffness when flexed. Physical properties of many materials can vary depending upon ambient temperature. A three point bending arrangement has been employed to carry out the bending test (Figures 18 and 19).

Testing procedure for bending: The arrangement for bending test is as shown in Figures 20 and 21. In this system, a center loading is utilized on a simply supported beam. Test specimens were according to the ASTM standard (D790) and the geometry of the test specimen is $200^{*} 20^{*} 10 \mathrm{~mm}$. The span length for loading specimen. A constant rate of loading, was applied on the specimen by using suitable weights. The number of the divisions on dial gauge was noted for all the loads applied and finally the load at which the specimen fails was noted down.

The above Figures 20 and 21 shows stress v/s strain graphs of bending test for specimens with different proportions of cob powder and resin. Proportion 40:60\% (specimen C) has maximum stiffness and maximum load before failure. And on the other hand, specimen of proportion 60:40\% (specimen A) has minimum stiffness. Thus we conclude that more the concentration of resin more strength is the particle board (Table 1).

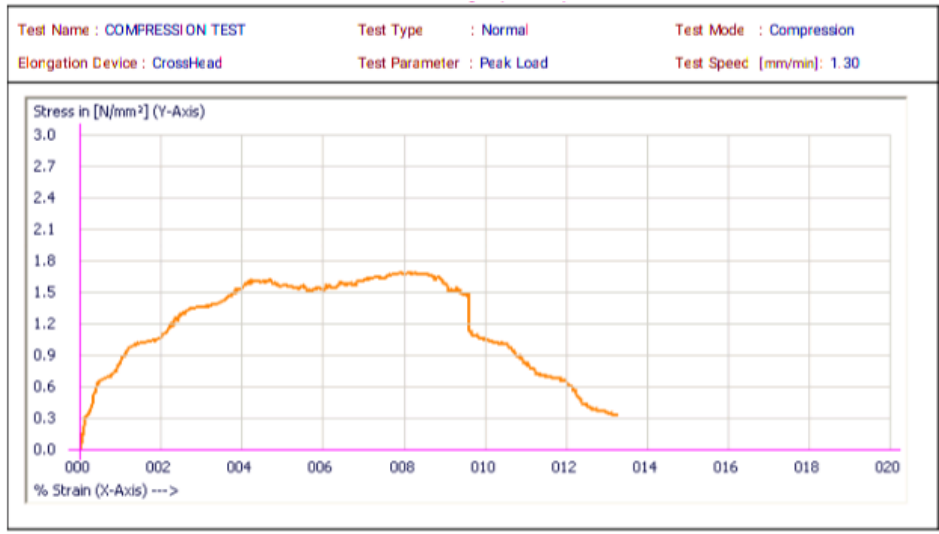

Sample Details :

\begin{tabular}{|c|c|c|c|c|c|c|}
\hline Sample No. & $\begin{array}{c}\text { CS Area } \\
\left(\mathrm{mm}^{2}\right)\end{array}$ & $\begin{array}{c}\text { Feak Loac } \\
(\mathrm{N})\end{array}$ & \% Elorgation & Break Load (N) & $\begin{array}{c}\text { Compressive } \\
\text { Sirençtr } \\
\left(\mathrm{N} / \mathrm{mm}^{2}\right)\end{array}$ & $\begin{array}{c}\text { Yourgs } \\
\text { Noculus } \\
\left(\mathrm{N} / \mathrm{mm}^{2}\right)\end{array}$ \\
\hline 000001 & 200.00 & 337.00 & 13.27 & & 1.69 & 0 \\
\hline
\end{tabular}

Figure 15: Compression test of specimen A 


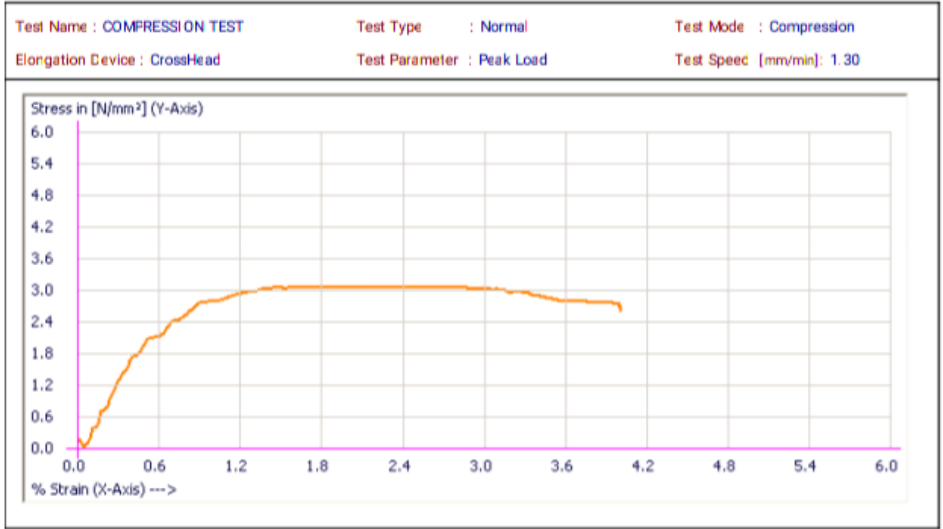

Sample Details :

\begin{tabular}{|c|c|c|c|c|c|c|}
\hline Sample No. & $\begin{array}{c}\text { CS Area } \\
\left(\mathrm{mm}^{2}\right)\end{array}$ & $\begin{array}{c}\text { Feak Loac } \\
(\mathrm{N})\end{array}$ & \% Elorgation & Break Load (N) & $\begin{array}{c}\text { Compressive } \\
\text { Sirencth } \\
\left(\mathrm{N} / \mathrm{mm}^{2}\right)\end{array}$ & $\begin{array}{c}\text { Yourgs } \\
\text { Noculus } \\
\left(\mathrm{N} / \mathrm{mm}^{2}\right)\end{array}$ \\
\hline 000001 & 200.00 & 612.00 & 4.01 & 64.75 & 3.06 & 0 \\
\hline
\end{tabular}

Figure 16: Compression test of specimen B.

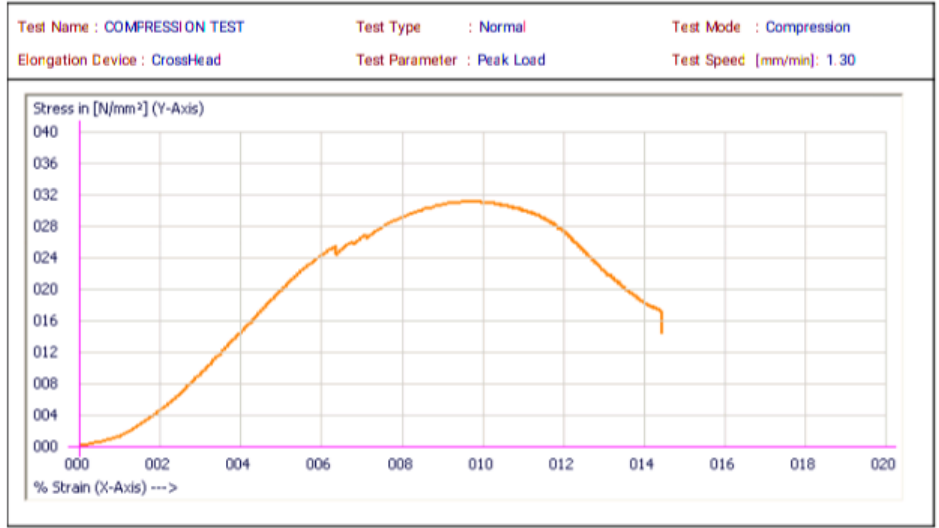

Sample Details :

\begin{tabular}{|c|c|c|c|c|c|c|}
\hline Sample No. & $\begin{array}{c}\text { CS Area } \\
\left(\mathrm{mm}^{2}\right)\end{array}$ & $\begin{array}{c}\text { Feak Loac } \\
(\mathrm{N})\end{array}$ & \% Elorgation & Break Load (N) & $\begin{array}{c}\text { Compressive } \\
\text { Strensth } \\
\left(\mathrm{N} / \mathrm{mm}^{2}\right)\end{array}$ & $\begin{array}{c}\text { Yourgs } \\
\text { Noculus } \\
\left(\mathrm{N} / \mathrm{mm}^{2}\right)\end{array}$ \\
\hline 000001 & 200.00 & 6.211 .00 & 14.43 & 24.30 & 31.06 & 0 \\
\hline
\end{tabular}

Figure 17: Compression test of specimen C.

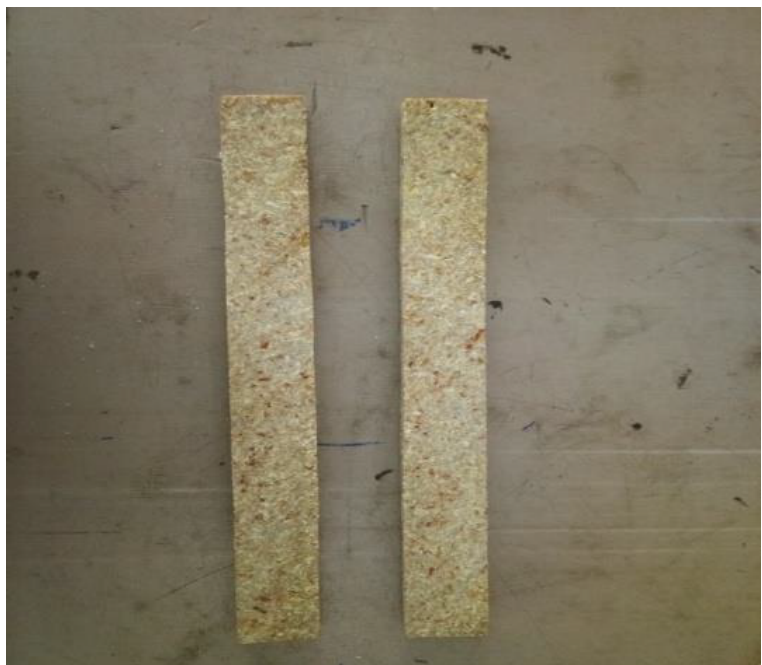

Figure 18: Specimens for bending test.

\section{APPLICATIONS}

1. Furniture,

2. Flooring,

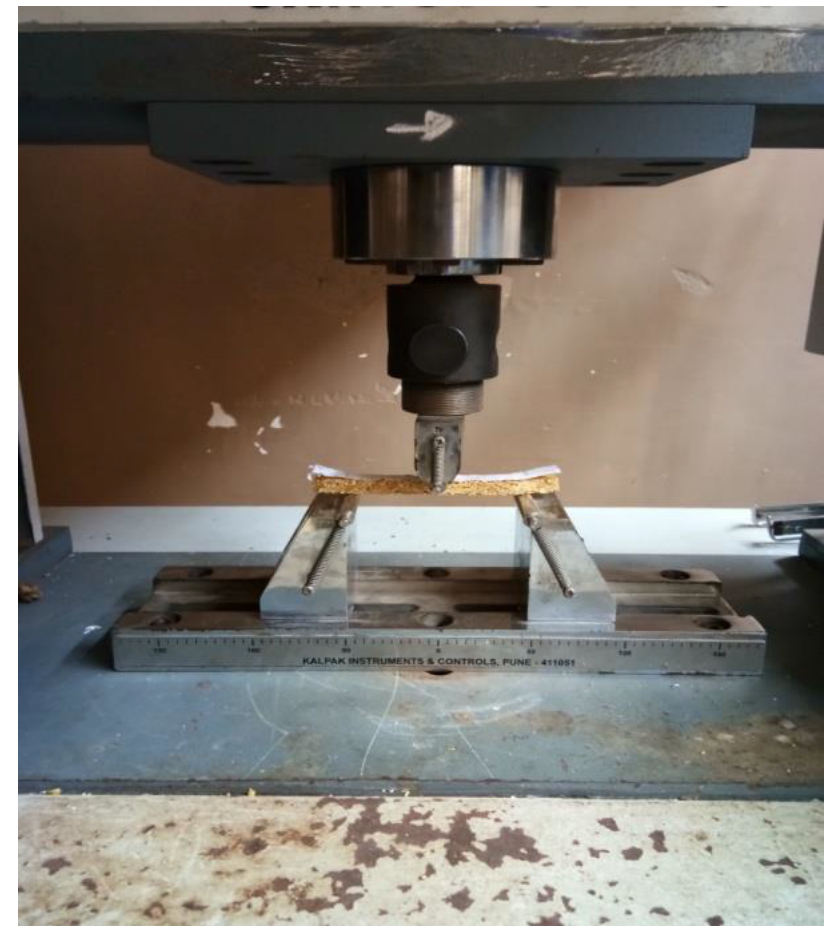

Figure 19: Setup and bending test of specimen A. 


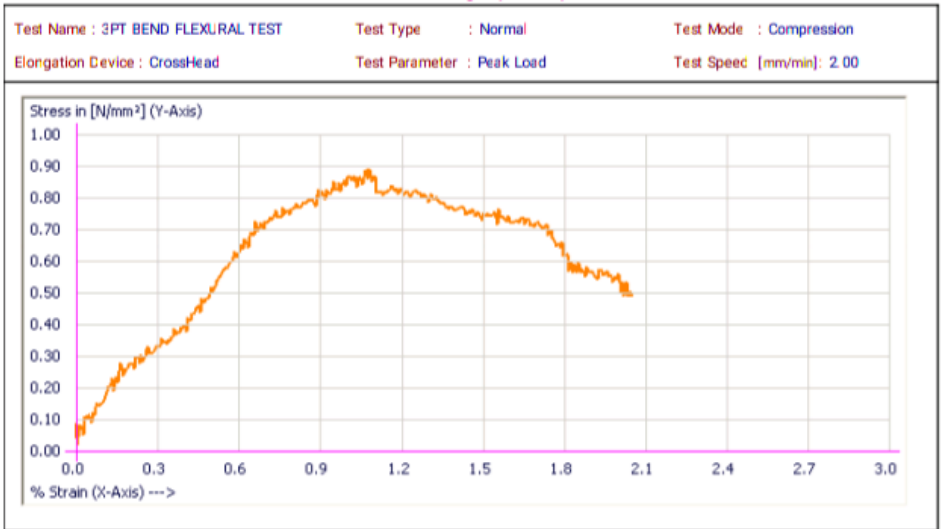

Sample Details :

\begin{tabular}{|c|c|c|c|c|c|c|}
\hline Sample No. & $\begin{array}{c}\text { CS Area } \\
\left(\mathrm{mm}^{2}\right)\end{array}$ & $\begin{array}{c}\text { Feak Loac } \\
(\mathrm{N})\end{array}$ & \% Elorgation & Break Load (N) & $\begin{array}{c}\text { 3Pt Benc } \\
\text { Flexural } \\
\text { Strergth (NPa) }\end{array}$ & $\begin{array}{c}\text { 3Pt Berd } \\
\text { Flexural } \\
\text { Moculi (GPa) }\end{array}$ \\
\hline 000000 & 120.00 & 107.00 & 2.06 & 1.30 & 10.66 & .196 .59 \\
\hline
\end{tabular}

Figure 20: Bend test of specimen B.

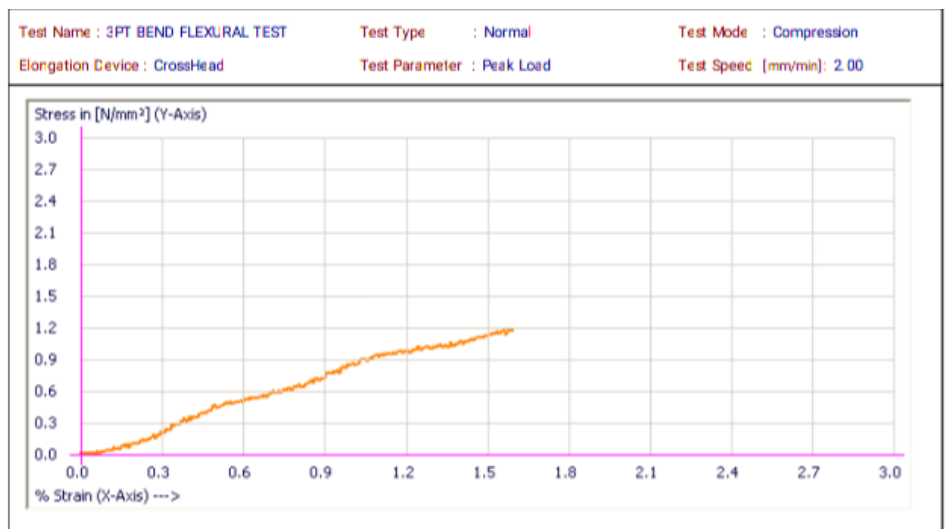

Sample Details :

\begin{tabular}{|c|c|c|c|c|c|c|}
\hline Sample No. & $\begin{array}{c}\text { CS Area } \\
\left(\mathrm{mm}^{2}\right)\end{array}$ & $\begin{array}{c}\text { Feak Loac } \\
(\mathrm{N})\end{array}$ & \% Elorgation & Break Load (N) & $\begin{array}{c}\text { 3Pt Benc } \\
\text { Flexural } \\
\text { Strergth (NPa) }\end{array}$ & $\begin{array}{c}\text { 3Pt Berd } \\
\text { Flexural } \\
\text { Moculi (GPa) }\end{array}$ \\
\hline 000001 & 120.00 & 141.00 & 1.60 & 105.28 & 14.13 & 103.15 \\
\hline
\end{tabular}

Figure 21: Bend test of specimen C.

Table 1: Testing of particle board composite.

\begin{tabular}{ccccc}
\hline Specimen & Raw material: Resin & Tensile Test UTS $\left(\mathrm{N} / \mathrm{mm}^{2}\right)$ & Compression Test $\left(\mathrm{N} / \mathrm{mm}^{2}\right)$ & Bending Test $\left(\mathrm{N} / \mathrm{mm}^{2}\right)$ \\
\hline A & $60: 40$ & 0.69 & 0.69 & - \\
\hline B & $50: 50$ & 4.60 & 4.60 & 10.66 \\
C & $40: 60$ & 5.09 & 5.09 & 14.13 \\
\hline
\end{tabular}

3. Roofing,

4. Sound proofing,

5. Photo lamination,

6. Speaker box,

7. Cabinet making,

8. Low cost housing,

9. Packaging boxes,

10. False ceiling,

11. Building partition,

12. Insulation.

\section{CONCLUSION}

From the results of the work reported, it can be explained that production of particle boards using maize cob and epoxy is feasible. The fundamental properties of the particle boards study show that the boars are strong enough to meet the essential requirements for useful outlets. Perhaps it will be necessary to put the required finishing having aesthetic products. The board produced can be used for general requirements such as partitioning materials, ceiling, table top and furnishings of house and commercial establishments etc.

\section{REFERENCES}

1. Danladi A, Patrick IO. World Academy of science, Engineering and Technology. International journal of Chemical, Molecular, Nuclear, Materials and Metallurgical Engineering. 2013;7:10. 
2. Muruganandam L, Ranjitha J, Harshavardhan A. A Review Report on Physical and Mechanical Properties of Particle Boards from Organic Waste. International Journal of ChemTech Research. 2016;9:64-72.

3. Iman Taha, Mohamad S Elkafafy, Hemmed El Mously. Potential of utilizing tomato stalk as raw material for particle boards. Ain Shams University, El-Sarayat Str. Cairo, Egypt. 2016;1:11517.

4. Mamza PAP, Shadrach K. The mechanical properties of urea formaldehyde Particle boards. International Journal of Pure and Applied Sciences. 2008;2:15-21.
5. Amenaghawon NA, Osayuki-Aguevor W, Okieimen CO. Production of particle boards from corn cobs and cassava stalks: optimization of mechanical properties using response surface methodology. J Mater Environ Sci. 2016;7:1236-1244.

6. Anderson A, Yung A, Tanaka T. Eco-Friendly Alternatives to WoodBased Particle Board. 2005.

7. Cheng E, Sun X, Karr GS. Adhesive Properties of modified soy bean flour in wheat straw particle board. Compos Part-A Appl Sci Manuf. 2004;35:297-302. 